\title{
Dexamethasone treatment in preterm infants at risk for bronchopulmonary dysplasia
}

\author{
M A Kari, K Heinonen, R S Ikonen, M Koivisto, K O Raivio
}

\begin{abstract}
A randomised double blind placebo controlled study was conducted to determine whether a one week course of dexamethasone could reduce the severity of bronchopulmonary dysplasia in preterm infants without compromising their adrenal function. Forty one infants with a mean birth weight of $880 \mathrm{~g}$ and a gestational age of 27 weeks who were ventilator dependent at 10 days of age were enrolled. At the age of 28 days pulmonary outcome was significantly better in the girls treated with dexamethasone but not in all infants. There was no difference between the groups in the long term outcome, except for a shorter duration of supplemental oxygen in dexamethasone treated female infants. After the one week dexamethasone treatment there was a significant but short lived suppression of the basal cortisol concentrations and the adrenal response to corticotrophin (ACTH). No serious side effects were observed.

It is concluded that early one week dexamethasone treatment improves short term pulmonary outcome in premature infants, but there is no clear evidence of long term benefits.
\end{abstract}

(Arch Dis Child 1993; 68: 566-569)

In spite of improvement in the outcome of very low birthweight (VLBW) infants, bronchopulmonary dysplasia remains a major cause of long term morbidity. ${ }^{1-3}$ Glucocorticoids are widely used for the treatment of bronchopulmonary dysplasia. This practice is based on several clinical trials, mostly with fairly small sample size, variable age and criteria for starting treatment, and variable criteria for evaluating outcome..$^{4-8}$ In a large international multicentre trial a one week course of dexamethasone at a constant dose of $0.6 \mathrm{mg} / \mathrm{kg} /$ day was given, ${ }^{9}$ whereas most of the others have used the dosage originally suggested by Avery et $a l,{ }^{4} \quad 0.5$ $\mathrm{mg} / \mathrm{kg} /$ day for three days, with variable length of tapering. In most studies steroids were allowed after the completion of the trial drug, further complicating the evaluation of the long term prognosis.

The aim of this multicentre trial was to assess whether a one week high dose course of dexamethasone, started at the age of 10 days, improves oxygenation to allow weaning of ventilator dependent VLBW infants, whether it reduces the severity of bronchopulmonary dysplasia, and whether it is safe.
Patients and methods

PATIENTS AND STUDY DESIGN

The study was conducted at four hospitals: the Children's Hospital, University of Helsinki; Department of Paediatrics, University of Kuopio; Department of Paediatrics, University of Oulu; and Department of Paediatrics, University of Tampere. The study design was approved by the ethical committees of all participating hospitals. The entry criteria were: (a) birth weight $1500 \mathrm{~g}$ or less; (b) gestational age 24 weeks or more; (c) dependence on mechanical ventilation at 10 days of age; and (d) no signs of patent ductus arteriosus, sepsis, gastrointestinal bleeding, or major malformation at entry.

After informed consent was obtained from the parents, eligible infants were randomised to receive a seven day course of either dexamethasone or placebo. Clinicians and investigators were unaware of treatment assignments. Randomisation was performed in blocks of 10 for each participating hospital. The infants in the dexamethasone group received $0.5 \mathrm{mg} / \mathrm{kg} /$ day dexamethasone sodium phosphate (Oradexon, Organon) intravenously in two doses for seven days, whereas infants in the placebo group received $0.9 \%$ saline.

Before entry, after the one week treatment period, and at the age of 28 days a two hour corticotrophin (ACTH) test was performed on all study infants. Blood samples were obtained from an indwelling arterial line, by venipuncture, or by heel stick before (basal sample) and two hours after (stimulated sample) an intravenous injection of $145 \mu \mathrm{g} / \mathrm{m}^{2}$ tetracosactrin (S-Cortrophin, Organon). All tests were started between 8 and 10 am. Serum cortisol was measured with a cortisol radioimmunoassay kit (Farmos Diagnostica); free and antibody bound cortisol were separated by polyethylene glycol precipitation.

Other forms of treatment were not strictly standardised. For all infants supplemental oxygen and mechanical ventilation were adjusted to maintain arterial or transcutaneous oxygen tension with $6 \cdot 5-9 \cdot 1 \mathrm{kPa}(50-70 \mathrm{~mm}$ $\mathrm{Hg}$ ) or oxygen saturation of haemoglobin within $88-95 \%$, and arterial or capillary carbon dioxide tension between 5.8 and $7.8 \mathrm{kPa}$ $(45-60 \mathrm{~mm} \mathrm{Hg})$. Ventilatory support was usually provided with a pressure limited ventilator, Baby-Bird (Bird Corporation), and only two infants were treated with a volumetric diffusive respirator (VDR Models 2 and 4, Bird Corporation). Blood gas measurements and chest radiographs were obtained as clinically indicated, as were other laboratory measurements. Glucocorticoid treatment was 
allowed after the age of 28 days at the discretion of the doctor.

\section{OUTCOME CRITERIA}

The results of treatment were evaluated primarily on the basis of neonatal pulmonary outcome. Poor pulmonary outcome was defined as dependence on mechanical ventilation at 28 days or death by that age. On the basis of a retrospective review at the Children's Hospital, University of Helsinki (1984-6), the incidence of such an outcome was $65 \%$ in VLBW infants who were ventilator dependent at 10 days of age. To detect a reduction to $40 \%$ in poor pulmonary outcome at 28 days (power $80 \%$, type 2 error less than 5\%), a minimal sample size of 79 in the two groups was estimated. Based on the rate of VLBW infants in the

Table 1 Clinical characteristics of infants before entry into the study. Values are number (\%) of infants or mean (SD)

\begin{tabular}{lccc}
\hline Characteristic & $\begin{array}{c}\text { Dexamethasone } \\
\text { group }(n=17)\end{array}$ & $\begin{array}{c}\text { Placebo group } \\
(n=24)\end{array}$ & $p$ Value * \\
\hline Birth weight (g) & $880(194)$ & $880(194)$ & NS \\
Gestational age (weeks) & $27(2)$ & $27(2)$ & NS \\
Males & $11(65)$ & $8(33)$ & NS \\
Intrauterine growth retardation (<-2 SD) & $5(29)$ & $3(13)$ & NS \\
Pulmonary air leak & $6(35)$ & $6(25)$ & NS \\
$\quad$ Pneumothorax & $4(24)$ & $3(13)$ & NS \\
Interstitial emphysema & $2(12)$ & $3(13)$ & NS \\
Patent ductus arteriosus (treatment) & $9(53)$ & $18(75)$ & NS \\
Intraventricular haemorrhage & $4(24)$ & $8(33)$ & NS \\
Grade 1-2 & $2(12)$ & $4(17)$ & NS \\
Grade 3-4 & $2(12)$ & $4(17)$ & NS \\
Age at start of trial drug (days) & $14(3)$ & $13(3)$ & \\
\hline
\end{tabular}

${ }^{\star} t$ Test or $\chi^{2}$ test.

Table 2 Ventilation parameters before and during the treatment period. Values are number (\%) of infants or median (quartiles)

\begin{tabular}{|c|c|c|c|}
\hline Variable & $\begin{array}{l}\text { Dexamethasone } \\
\text { group }(n=17)\end{array}$ & $\begin{array}{l}\text { Placebo group } \\
(n=24)\end{array}$ & p Value \\
\hline \multicolumn{4}{|c|}{ Ventilator dependency } \\
\hline Before treatment & 17 & 24 & NS \\
\hline After five days & $12(71)$ & $17(71)$ & NS \\
\hline After seven days & $8(47)$ & $19(79)$ & NS \\
\hline \multicolumn{4}{|c|}{ Rate of ventilation (cycles/min) } \\
\hline Before treatment & $23(19-38)$ & $28(12-45)$ & NS \\
\hline After five days & $17(13-27)$ & $32(22-44)$ & 0.033 \\
\hline After seven days & $22(16-31)$ & $29(25-39)$ & NS \\
\hline \multicolumn{4}{|c|}{ Peak inspiratory pressure $\left(\mathrm{cm} \mathrm{H}_{2} \mathrm{O}\right)$} \\
\hline Before treatment & $18(18-20)$ & $19(18-21)$ & NS \\
\hline After five days & $18(16-20)$ & $21(17-22)$ & 0.047 \\
\hline After seven days & $19(17-22)$ & $21(18-23)$ & NS \\
\hline \multicolumn{4}{|c|}{ Fractional inspired oxygen concentration } \\
\hline Before treatment & $0.35(0.25-0.43)$ & $0.39(0.26-0.55)$ & \\
\hline After five days & $0.28(0.25-0.35)$ & $0.40(0.33-0.58)$ & 0.008 \\
\hline After seven days & $0 \cdot 25(0 \cdot 22-0 \cdot 36)$ & $0.35(0.30-0.51)$ & 0.032 \\
\hline
\end{tabular}

${ }^{\star}$ Mann-Whitney $U$ test or $\chi^{2}$ test.

Table 3 Outcome at the age of 28 days. Values are number (\%) of infants

\begin{tabular}{|c|c|c|c|}
\hline & $\begin{array}{l}\text { Dexamethasone } \\
\text { group }\end{array}$ & Placebo group & p Value $*$ \\
\hline All infants & $\mathrm{n}=17$ & $\mathrm{n}=24$ & \\
\hline Poor pulmonary outcome $\dagger$ & $8(47)$ & $18(75)$ & NS \\
\hline Weaned from ventilator & $9(53)$ & $6(25)$ & \\
\hline With oxygen & $7(41)$ & $5(21)$ & \\
\hline Without supplementary oxygen & $2(12)$ & $1(4)$ & \\
\hline Boys & $n=11$ & $\mathrm{n}=8$ & \\
\hline Poor pulmonary outcome & $7(64)$ & $6(75)$ & NS \\
\hline Weaned from ventilator & $4(36)$ & $2(25)$ & \\
\hline With oxygen & $4(36)$ & $1(13)$ & \\
\hline Without supplementary oxygen & 0 & $1(13)$ & \\
\hline Girls & $n=6$ & $n=16$ & \\
\hline Poor pulmonary outcome $\dagger$ & $1(17)$ & $12(75)$ & 0.046 \\
\hline Weaned from ventilator & $5(83)$ & $4(25)$ & \\
\hline With oxygen & $3(50)$ & $4(25)$ & \\
\hline Without supplementary oxygen & $2(33)$ & 0 & \\
\hline
\end{tabular}

${ }^{\star} \chi^{2}$ test.
†Death or ventilator dependency. country $(0.7 \%)$ and the proportion of these treated at the participating hospitals, a duration of patient recruitment of 18 months was projected.

Bronchopulmonary dysplasia was defined according to the criteria described by Bancalari et al. $^{2}$ Hypertension was defined as a systolic blood pressure of $\geqslant 95 \mathrm{~mm} \mathrm{Hg}$ measured at least twice with an automatic sphygmomanometer (Dinamap, Critikon Inc). ${ }^{10}$ Hyperglycaemia was defined as a blood glucose concentration $\geqslant 8.0 \mathrm{mmol} / \mathrm{l}$ in at least two separate samples. Sepsis was defined as a positive blood culture. Central nervous system abnormalities were identified by serial cranial ultrasonography. An ophthalmologist examined the infants from the age of 4-6 weeks and evaluated the need for cryotherapy.

\section{STATISTICAL TESTS}

Continuous variables were compared with Student's two sided $t$ test or the MannWhitney $U$ test. Categorical variables were compared by the $\chi^{2}$ test. A p value less than 0.05 was considered significant.

\section{Results}

From January 1989 to February 1991, 41 infants were enrolled, 17 into the dexamethasone and 24 into the placebo group. The number of infants recruited was only $25 \%$ of the $a$ priori assumption. The study was therefore discontinued after 26 months.

Table 1 shows the clinical characteristics of the patients before entry into the study. There was no significant difference between the groups even though the sex distribution was uneven. Both in the dexamethasone and placebo groups one infant had received dexamethasone prenatally at least 24 hours before birth. Three infants in the dexamethasone group and one infant in the placebo group had received human surfactant during the first 72 hours of life. ${ }^{11}$ Two female infants in the control group were withdrawn, one by her doctor and one by her parents, and the trial drug treatment of these two infants was stopped. These infants are included in the outcome analysis.

During the treatment period, the infants who received dexamethasone needed significantly less supplemental oxygen (table 2). There were also reductions in other ventilatory settings. Table 3 summarises the outcome at 28 days of age. There was no difference between the groups in the pulmonary outcome in all or male infants, but female infants treated with dexamethasone had a significantly better pulmonary outcome at 28 days of age $(p=0.046)$. There were two deaths by that age in the placebo group. One male infant of 29 weeks' gestation died at the age of 21 days of respiratory failure and a girl of 25 weeks' gestation at the age of 28 days of grade 4 intraventricular haemorrhage and periventricular leucomalacia. These two infants were ventilator dependent until death. Weight gain was similar in the two groups. Median weight at the 
age of 28 days was $969 \mathrm{~g}$ in the dexamethasone and $1002 \mathrm{~g}$ in the placebo group.

Table 4 summarises the long term outcome by the age of 1 year. There were two late deaths. One boy in the dexamethasone group died at the age of 125 days of bleeding after craniosynostosis surgery, two weeks after weaning from the respirator, and still receiving supplemental oxygen. A girl in the placebo group died at the age of 34 days of necrotising enterocolitis and sepsis; she was ventilator dependent until death. The overall mortality rate was $9 \cdot 8 \%$. There was no significant difference in the mortality between the groups $(5.9 \%$ in the dexamethasone and $12.5 \%$ in the placebo group). Even though the primary cause of death was different, all the infants who died had bronchopulmonary dysplasia.

The other measures of long term outcome were not significantly different between the dexamethasone and placebo groups except that female infants treated with dexamethasone needed a shorter time of supplemental oxygen $(p=0 \cdot 047)$. After 28 days of age dexamethasone was given to six $(35 \%)$ infants in the dexamethasone and to eight (33\%) infants in the placebo group. The duration of hospital stay in survivors was similar in the two groups; in the dexamethasone group the median duration of hospital stay was 109 days and in the placebo group 114 days. With one exception the survivors were weaned from supplemental oxygen by

Table 4 Long term outcome in survivors. Values are medians (quartiles)

\begin{tabular}{llll} 
& $\begin{array}{l}\text { Dexamethasone } \\
\text { group }\end{array}$ & Placebo group & p Value* \\
\hline All infants & $\mathrm{n}=16$ & $\mathrm{n}=21$ & \\
$\quad$ Mechanical ventilation (days) & $24(20-40)$ & $40(22-50)$ & $\mathrm{NS}$ \\
$\quad$ Oxygen treatment (days) & $55(36-94)$ & $68(52-112)$ & $\mathrm{NS}$ \\
Boys & $\mathrm{n}=10$ & $\mathrm{n}=7$ & $\mathrm{~N}$ \\
$\quad$ Mechanical ventilation (days) & $29(16-40)$ & $36(20-44)$ & $\mathrm{NS}$ \\
$\quad$ Oxygen treatment (days) & $64(54-103)$ & $62(47-68)$ & $\mathrm{n}=14$ \\
Girls & $\mathrm{n}=6$ & $43(23-57)$ & $\mathrm{NS}$ \\
$\quad$ Mechanical ventilation (days) & $24(22-30)$ & $96(53-126)$ & $0 \cdot 047$ \\
Oxygen treatment (days) & $36(24-46)$ & &
\end{tabular}

^Mann-Whitney U test.

Table 5 Basal and stimulated cortisol concentrations (nmoll). Values are medians (quartiles)

\begin{tabular}{|c|c|c|c|}
\hline & $\begin{array}{l}\text { Dexamethasone } \\
\text { group }(n=17)\end{array}$ & $\begin{array}{l}\text { Placebo group } \\
(n=24)\end{array}$ & p Value ${ }^{*}$ \\
\hline \multicolumn{4}{|l|}{ At entry } \\
\hline Basal cortisol & $137(92-193)$ & $123(85-160)$ & NS \\
\hline Stimulated cortisol & $740(325-878)$ & $640(394-847)$ & NS \\
\hline$\Delta$ Cortisol & $480(235-749)$ & $509(310-609)$ & NS \\
\hline \multicolumn{4}{|l|}{ After seven days } \\
\hline Basal cortisol & $55(39-118)$ & $160(109-224)$ & 0.002 \\
\hline Stimulated cortisol & $468(302-615)$ & $704(510-989)$ & 0.030 \\
\hline$\Delta$ Cortisol & $423(244-480)$ & $419(341-803)$ & NS \\
\hline \multicolumn{4}{|l|}{ At 28 days of age } \\
\hline Basal cortisol & $118(71-213)$ & $137(92-317)$ & NS \\
\hline Stimulated cortisol & $701(499-1013)$ & $1106(873-1375)$ & 0.032 \\
\hline$\Delta$ Cortisol & $451(355-890)$ & $953(740-1083)$ & 0.024 \\
\hline
\end{tabular}

Table 6 Complications during the treatment period and by 28 days. Values are number (\%) of infants

\begin{tabular}{llll}
\hline & $\begin{array}{l}\text { Dexamethasone } \\
\text { group }(n=17)\end{array}$ & $\begin{array}{l}\text { Placebo group } \\
(n=24)\end{array}$ & $p$ Value $^{*}$ \\
\hline $\begin{array}{llll}\text { Hyperglycaemia } \\
\text { Hypertension }\end{array}$ & $6(35)$ & $4(17)$ & NS \\
Sepsis & $7(41)$ & $1(4)$ & $0 \cdot 011$ \\
Perforation of the colon & $4(24)$ & $2(8)$ & NS \\
\end{tabular}

${ }^{\star} \chi^{2}$ test.
1 year of age. Three infants in the dexamethasone and one infant in the placebo group needed cryotherapy for retinopathy of prematurity.

Before entry into the study basal and stimulated cortisol concentrations and $\Delta$ cortisol were similar in the dexamethasone and placebo group (table 5). After the one week treatment period basal and stimulated cortisol concentrations were significantly lower in the dexamethasone than in the placebo group. At the age of 28 days there was no difference in the basal cortisol concentrations between the groups, but the stimulated cortisol and $\Delta$ cortisol were still significantly lower in the dexamethasone group.

Complications occurred after study entry in both groups (table 6). The incidence of sepsis and hyperglycaemia was similar, but hypertension developed significantly more often in the dexamethasone group $(p=0 \cdot 01)$. The blood pressure became normal in all infants after the treatment period and none needed treatment for hypertension at discharge. Perforation of the colon, caused by necrotising enterocolitis, occurred in two infants in the placebo group.

\section{Discussion}

We did not succeed in enrolling the projected number of patients for our trial. To assess whether this was due to changes in the composition of the patient material, we reviewed the statistics of the Children's Hospital, University of Helsinki, which is the largest of the participating units. Of the 241 VLBW infants (birth weight less than $1500 \mathrm{~g}$ ) treated in 1984-6, the proportion of those weighing less than $1000 \mathrm{~g}$ was $34 \%$, but this proportion was $48 \%$ of the 216 VLBW infants treated between 1 January 1989 and 28 February 1991. Mortality was practically unchanged (25 $v 24 \%$ respectively), but whereas during the former time period $34 \%$ of VLBW infants were on a respirator at 10 days of age, that proportion during the latter years was only $26 \%$. Thus a decrease in chronic respiratory morbidity, despite a greater number of tiny infants, only partly accounts for the problems of recruitment in our study. A more indepth analysis of the reasons for not achieving the projected number of patients did not seem useful, but similar problems have obviously been encountered elsewhere. With the exception of the multicentre study, ${ }^{9}$ all of the controlled trials of glucocorticoids in bronchopulmonary dysplasia have included fewer patients than ours.

Many VLBW infants with respiratory distress syndrome do not recover from the acute lung injury and develop bronchopulmonary dysplasia. The pathogenesis of this process is still unclear. The mechanism of action of corticosteroids in infants with chronic lung disease also remains unclear. Several modes of action have been suggested: decrease of lung water, increase of surfactant synthesis, and reduction of inflammatory damage in the lungs. ${ }^{12-14}$ In ventilator dependent VLBW infants, a three day course of dexamethasone treatment was found to decrease the inflammatory process in the lungs and simultaneously improve pulmonary function. ${ }^{15}$ 
Previous small scale studies have suggested that the respiratory status of infants treated with dexamethasone, compared with control infants, improves in the short term, allowing earlier weaning from the respirator and thus shortening the duration of mechanical ventilation. ${ }^{458}$ In one study, neurodevelopmental outcome at one year appeared better in infants receiving a 42 day course of dexamethasone ${ }^{6}$ but this and all other studies did not show any improvement in the long term outcome in terms of mortality, length of stay in hospital or oxygen requirement, or incidence of serious complications.

At least two factors may account for the lack of observable effects of steroids in the long term. Firstly, in most studies steroid treatment was allowed and commonly given after the trial period. This would tend to dilute possible initial differences between treatment groups. For example, in the largest study reported, ${ }^{9}$ only $47 \%$ of infants in the placebo group did not receive any steroids. In our study, $67 \%$ of the placebo group were not treated with dexamethasone after the age of 28 days, though this would have been permissible.

The second factor is the timing of steroid treatment. Based on previous clinical experience, we chose to begin dexamethasone treatment depending on the situation at 10 days of age, which is earlier than in any other reported study. Our plan to administer a high dose, 0.5 $\mathrm{mg} / \mathrm{kg} /$ day, of dexamethasone for seven days was based on the expectation of achieving short term improvement sufficient for weaning from the respirator without causing adrenal suppression necessitating long term substitution treatment. Considering the evolution of bronchopulmonary dysplasia, with progressive fibrosis and pulmonary hypertension, it is probably unreasonable to expect much from treatment started late in the process. This may have been the problem in some previous studies. As shown in table 3, very few infants in either group survived without developing bronchopulmonary dysplasia. It seems that dependency on ventilator treatment at the age of 10 days is practically synonymous with chronic lung disease, and that dexamethasone or any other treatment started at that age cannot be considered prophylactic. If true prevention is the aim, earlier measures would be necessary. One report even suggests that glucocorticoids given in the first days of life may have a beneficial effect on the pulmonary outcome of respiratory distress syndrome. ${ }^{16}$

In general, our results are in line with those of others in that some benefit was demonstrable in the short term, but not in the long term. Long term benefits were seen only in female infants, but the small number of patients studied renders the conclusion tentative. In view of the well known effect of sex on the overall and respiratory distress syndrome mortality of VLBW infants, ${ }^{17} 18$ a female advantage in bronchopulmonary dysplasia outcome also would not be surprising. Our ACTH test results are consistent with earlier reports. ${ }^{6}$ 19-21 One week dexamethasone treatment suppressed significantly basal cortisol levels and adrenal response to ACTH, but the suppression was short lived and probably not clinically significant. At the age of 28 days, one week after discontinuation of the treatment, the basal cortisol concentrations and the adrenal response to ACTH could be regarded normal in most infants.

Several questions concerning the role of glucocorticoids in the prevention and treatment of bronchopulmonary dysplasia remain unanswered and further trials are clearly needed. Does the apparent short term benefit justify a treatment with potential complications and unknown side effects? If yes, what is the optimum age to start, what preparation, what dose, and how long? The study was supported by The Foundation for Pediatric
Research, The Academy of Finland, and The Sigfrid Juselius Research, The Academy of Finland, and The Sigfrid Juselius
Foundation. We thank Organon Company for providing the Foundation. We thank Organon Comp
dexamethasone and placebo ampoules. 1 Boynton RR. The epidemiology of bronchopulmonary dys-
plasia. In: Merritt TA, Northway WH, Boynton BR, eds. Bronchopulmonary dysplasia. Boston: Blackwell Scientific 1988: 19-32.

2 Bancalari E, Abdenour GE, Feller R, Gannon J. Bronchopulmonary dysplasia: clinical presentation. $\mathcal{F}$ Pediatr 1979 ; 95: 819-23.

3 Avery ME, Tooley WH, Keller JB, et al. Is chronic lung disease in low birth weight infants preventable? A survey of eight centers. Pediatrics 1987; 79: 26-30.

4 Avery GB, Fletcher AB, Kaplan M, Brudno DS. Controlled trial of dexamethasone in respirator-dependent infants with bronchopulmonary dysplasia. Pediatrics 1985; 75: 106-11.

5 Mammel MC, Green TP, Johnson DE, Thompson TR. Controlled trial of dexamethasone therapy in infants with bronchopulmonary dysplasia. Lancet 1983; i: 1356-8.

6 Cummings J, D'Eugenio DB, Gross SJ. A controlled trial of dexamethasone in preterm infants at high risk for bronchopulmonary dysplasia. $N$ Engl $f$ Med 1989; 320 1505-10.

7 Kazzy NJ, Brans YW, Poland RL. Dexamethasone effects on the hospital course of infants with bronchopulmonary dysplasia who are dependent on artificial ventilation. Pediatrics plasia who are depen

8 Harkavy KL, Scanlon JW, Chowdry PK, Grylack LJ. Dexamethasone therapy for chronic lung disease in ventilator- and oxygen-dependent infants: a controlled trial f Pediatr 1989; 115: 979-83.

9 Collaborative Dexamethasone Trial Group. Dexamethasone therapy in neonatal chronic lung disease: an international placebo-controlled trial. Pediatrics 1991; 88: 421-7.

10 Tan KL. Blood pressure in very low birth weight infants in the first 70 days of life. $\mathcal{F}$ Pediatr 1988; 112: 266-70

11 Merritt TA, Hallman M, Berry C, et al. Randomized, placebo-controlled trial of human surfactant given at birth versus rescue administration in very low birth weight infants with lung immaturity. $\mathcal{F}$ Pediatr 1991; 118: 581-94.

12 Ariagno RL. Use of steroids. In: Merritt TA, Northway WH, Boynton BR, eds. Bronchopulmonary dysplasia. Boston: Blackwell Scientific, 1988: 375-402.

13 Gerdes JS, Harris MC, Polin RA. Effects of dexamethasone and indomethacin on elastase, alfa1-proteinase inhibitor, and fibronectin in bronchoalveolar lavage fluid from neonates. F Pediatr 1988; 113: 727-31.

14 Frank L, Lewis PI, Sosenko IRS. Dexamethasone stimulation of fetal rat lung antioxidant enzyme activity in parallel with surfactant stimulation. Pediatrics $1985 ; 75$ : 569-74.

15 Yoder MC, Chua R, Tepper R. Effect of dexamethasone on pulmonary inflammation and pulmonary function of ventiputor-dependent infants with bronchopulmonary dysplasia. Am Rev Respir Dis 1991; 143: 1044-8.

16 Yeh TF, Torre JA, Rastogi A, Anyebuno MA, Pildes RS Early postnatal dexamethasone therapy in premature infants with severe respiratory distress syndrome: a doubleblind, controlled study. F Pediatr 1990; 117: 273-82.

17 Palta M, Gabbert D, Weinstein MR, Peters ME Multivariate assessment of traditional risk factors of chronic lung disease in very low birth weight neonates. $\mathcal{f}$ Pediatr 1991; 119: 285-92.

18 Horbar JD, McAuliffe TL, Adler SM, et al. Variability in 28day outcomes for very low birth weight infants: an analysis of 11 neonatal intensive care units. Pediatrics 1988: 82 554-9.

19 Wilson DM, Baldwin RB, Ariagno RL. A randomized, placebo-controlled trial of effects of dexamethasone on hypothalamic-pituitary-adrenal axis in preterm infants. hypodiatr 1988; 113: 764-8.

20 Alkalay AL, Pomerance JJ, Puri AR, et al. Hypothalamic-pituitary-adrenal axis function in very low birth weight infants itary-adrenal axis function in very low birth weight infants
treated with dexamethasone. Pediatrics $1990 ; 86: 204-10$.

21 Rizvi ZB, Aniol HS, Myers TF, Zeller WP, Fisher SG Anderson CL. Effects of dexamethasone on the hypothalamic-pituitary-adrenal axis in preterm infants. $\mathcal{F}$ Pediatr 1992; 120: 961-5. 